\title{
An Initial Study on the "Enlightening Points" Teaching Mode for College Freshmen from Intersubjectivity Perspective
}

\author{
Liu Jingyuan \\ 579 Qianwangang Road Economic \& Technical Development Zone, Qingdao Shandong Province, \\ 266510 P.R. China, 361645166@qq.com
}

Keywords: intersubjectivity; college freshmen; teaching mode

\begin{abstract}
A teaching mode refers to the relatively stable frameworks and procedures for teaching activities established under certain teaching ideas or theories. The current college teaching is facing new challenge of "enriching connotation, expanding denotation, improving efficiency", so it is urgent to reform the traditional teaching mode. Intersubjectivity provides a new perspective for reforming the college teaching mode, especially for teaching of college freshmen. With the analysis of intersubjective education characteristics, explanation of the profound connotation of "enlightening" in the ancient Chinese education thought "I do not open up the truth to one who is not eager to get knowledge, nor help out any one who is not anxious to explain himself", this paper explores to establish the "enlightening points" teaching mode for college freshmen from the perspective of intersubjectivity with the basic idea of "emphasizing beginning, enlightening learning”.
\end{abstract}

\section{It's the Basis of the "Enlightening Points" Teaching Mode to Understand Contemporary College Freshmen}

The current college freshmen are born after 1990s and known as the "post 90s". They have two characteristics:

One is the normal characteristics of students of this age after China's reforming and opening up for over 30 years. Firstly, they are between children and adults in physiology and psychology, and do not form their world outlooks, views on life and values; Secondly, they live in the "half-society" between family and society, in which they live independently with controlling power and self-restraint morality instead of family education; Thirdly, the education mode transforms from the passive acceptance in secondary school into self initiative acceptance in college, and the self-study ability becomes an important factor in enhance of performance and competence.

The other is the characteristics of the times of the "post 90s". Firstly, they are more rational. Moreover, they are more pragmatic, open and calm, more practical and flexible in choosing a job, and more grim and sober in mentality, and they pay more attention to rules of action and abilities when given a chance; Secondly, they are more humanistic, in other words, they are more human-oriented in views of values and strongly request democracy; Thirdly, they are more individual. They transmit social culture in flexible and various forms, and expand individuality from such personal life areas as clothing and hairstyle into the social life as participation and expression; Fourthly, they are more practical, they speak highly of living at present and prefer to get more qualifications rather than read more philosophy books; Fifthly, they are more recreational. They regard entertainment as a basic lifestyle from the beginning and often lead social entertainment trend; Sixthly, they are of more informationization. They can't get through without mobile phones and computers, to which they "outsource" their brains. They acquire information and knowledge mostly from the network outside lessons, "searching” becoming an indispensable way of life for them. In conclusion, the reform of teaching mode for contemporary college freshmen should be more targeted, more significant and respect for students' individuality more.

The "Enlightening Points" Teaching Mode is Based on the Philosophical View of Intersubjectivity and the Educational Concept of "I do not Open Up the Truth to One Who is 


\section{not Eager to Get Knowledge, nor Help Out Any One Who is not Anxious to Explain Himself”}

By American educator, B. Joyce's Teaching Mode, a teaching mode is the reflection of teaching theories or teaching thoughts, it specifies teaching behavior under certain theories. Different teaching modes are put forward under different education views, so does the "enlightening points" teaching mode.

Firstly, intersubjectivity is the philosophical theory of the "enlightening points" teaching mode. Intersubjectivity was first proposed by Husserl, a German philosopher, in the 20th century. It researches or rules how one subject interworks with another whole operating subject. Along with the emergence of intersubjectivity, social science appears a major turn in epistemology from the emphasis on subjectivity and relationship between "subject-object" into relationship between the subject and subject. On the other hand, the epistemology of intersubjectivity also changed its basic philosophical connotation of "existence", which considers the "existence" as the co-existence between different subjects. With the assimilation of intersubjectivity in philosophy into subject education, the subjective education will inevitably work up to intersubjectivity education. It's not a simple transplant of philosophical concepts but a natural development of the subject education that the subjectivity education evolves into intersubjectivity education. The subjectivity education theory has experienced a dialectical development of negation of negation from "center theory" to "subject-guide theory" and from "double subjects theory" to "intersubjectivity theory", among which, the "double subjects theory" is the transition of the dialectical development process as well as the key stage of the process. From the "double subjects" to "interactive subject", "interactive subjectivity" to "intersubjectivity", the "subjectivity education" has naturally developed into "intersubjectivity education", which is the starting point of the concept "emphasizing beginning, enlightening learning" of the "enlightening points" teaching mode.

Besides, the "enlightening points" teaching mode roots its theoretical guidance in the concept of "I do not open up the truth to one who is not eager to get knowledge, nor help out any one who is not anxious to explain himself", which comes from "I do not open up the truth to one who is not eager to get knowledge, nor help out any one who is not anxious to explain himself. When I have presented one corner of a subject to any one, and he cannot from it learn the other three, I do not repeat my lesson." of the Analects of Confucius. That's to say, a teacher should not teach students until they are still confused after trying hard to understand the questions, not enlighten them unless they understand but have difficulty to express themselves, and not continue to teach if they can't draw inferences about other cases from one instance. "Anxiety" is one ambivalent state that students are thinking questions positively but can't get it straight yet. At this time, the teacher should guide their way of thinking to help them open their mind, which is the "enlightening". "Be at a loss for words" is another ambivalent state that students are in difficult to express themselves without mature thought after thinking about a question for a period of time. It is the time for teachers to help them clarify ideas and essence of things and then express themselves with accurate words, which is the "sending". This concept just can facilitate most freshmen to break the bottleneck in the transition from accepted teaching to the autonomous teaching and it is also the focus of the concept "emphasizing beginning, enlightening learning” of the "enlightening points" teaching mode.

\section{To Achieve a Win-win Relationship for Teacher and Student Constitute the Teaching Objective of the "Enlightening Points" Teaching Mode}

Any teaching mode points to and achieves a certain teaching objective which is the core of a teaching mode structure and places restrictions on other factors of the teaching mode. As the standard and measure of teaching evaluation, teaching objective decides the operating procedures of teaching mode and relationship between teachers and students in teaching activities. It is the strong inner unity of teaching mode and teaching objective that determines characteristics of different teaching modes, which serve for certain teaching objectives. The teaching objective of the "enlightening points" teaching mode is to build an intersubjective relationship between teacher and 
student so as to achieve a win-win situation in the teaching process. The cognitive attitude and value orientation we hold play a key role in how to treat the intersubjective relationship between teacher and student. In terms of the cognitive attitude, teachers should not only regard students as children but also treat and cultivate them as subjectivity persons. In terms of the value orientation, the subjectivity between teacher and student should be realized on the basis of the intersubjective relationship to achieve coexistence rather than the subjectivity of self-centeredness under opposite relation of subjective-objective. In teaching activities, the teacher is the subjective to impart knowledge and the student is the subjective to actively participate. They both benefit from the teaching activities in which students not only acquire knowledge and skills, but also learn the principles, and learn how get along with others. The intersubjectivity theory endows educational significance to relationship between teacher and student, enhancing it from the fundamental condition of teaching activities to the new position with educational significance. Therefore, it will greatly enrich the connotation of the "enlightening points" teaching mode to make establishment of intersubjective relationship between teacher and student as a teaching goal.

\section{It's the Concrete Step and Mean of the "Enlightening Points" Teaching Mode to Hold the Five Key Points of "Virtue, Learning, Thinking, Interest, and Perspective"}

Each teaching mode has its specific steps and procedures, which rules what teachers and students do at first and then and what mission each step should complete during teaching activities. The "enlightening points" teaching mode is no exception.

Firstly, "enlighten virtue”, namely shape noble characters, which is of fundamental importance. Freshmen learn to behave by cultivating personalities and establish correct self-concepts with sound psychological. In this respect, freshmen are easily bored with repeating book knowledge while instructions by words and deeds from teachers will be more effective.

Secondly, "enlighten learning”, namely open the door of knowledge. "It's better to teach a man fishing than to give him a fish.” By developing good study habits, freshmen can learn how to study and create, and quickly adapt to the pace of college life. Teachers can assign readings for students and teach them to make full use of the library resources to make them realize differences between high school study and college study-the latter emphasizes on self-learning with learning tools.

Thirdly, "enlighten thinking”, namely improve the ability to research. "Learning without thought is labor lost; thought without learning is perilous." It is easy to be deceived and restricted by predecessors' ideas for students if they study mechanically without their own discriminations and judgments. There is no doubt that teachers have knowledge, but the lectures they give may be defective even incorrect with a few problems having not been solved by predecessors. In this case, it will lay a solid foundation of thinking for college freshmen in the future studies to encourage students to ask more questions and often say "no", to inspire them to think and study more.

Fourthly, "enlighten interest", namely cultivate interest in learning. The development of the interest in learning is closely related to teaching. Cultivation of interest in learning of freshmen mainly relies on the majors they choose and that whether college teaching activities can make them get interested in learning. In terms of this, the author thinks it's imperative to comprehend each student's characteristic, generalize their common features so as to design teaching contents with a target goal. Teachers should put forward questions students are passionate about, analyze and solve the questions together with them to cultivate sense of curiosity and sense of achievement in learning of the students. At this point, it is a desirable way to make use of teaching aids with high-tech multimedia or to hold distinctive small quizzes and contests.

Fifthly, “enlighten perspective”, namely broaden views for learning. Restricted by lower teacher strength and knowledge level, teaching in middle school can't be comparable with that in college in the breadth, depth and height of knowledge. Lectures, BBS and art exchange activities on professions are epitome of high-end culture of colleges. It is believed that attend such activities more often can expand horizons of students, which is beneficial to them. So it is an ideal way of promoting learning perspectives and expanding knowledge of the freshmen to develop teaching of high-end thinking with diversified teaching means as well as abundant education resources in 
college.

In one word, intersubjectivity is ideal theoretically, but is inadequate and realistic practically. The realization of the education and teaching under intersubjectivity philosophy is influenced by several factors, especially the individual differences of students, thus it bears large dynamic nature and uncertainty and can't achieve immediate effects in a short period. Only with cooperation of all teachers in colleges, specific and in-depth analysis can we grasp the interactive relationship between teacher and student to constantly make teaching of college freshmen more scientific and artistic, to show a scientific path of seeking knowledge for them at the beginning so as to continuously improve education quality of colleges and promote development of education to cultivate new era students with higher quality and capability for our country.

\section{References}

[1] Joyce: Teaching Mode, China Light Industry Press, Beijing (2002).

[2] Xing Yongfu: Modern Education Thoughts, Central Radio \& TV University Press, Beijing (2001).

[3] Liu Fangtong: Modern Western Philosophy, People’s Publishing House, Beijing (1988).

[4] Safranski: Biography of Heidegger, The Commercial Press, Beijing (1999).

[5] Yang Chunshi: Literary Theory: from Subjectivity to Intersubjectivity, Xinhua Digest (2002). 